\title{
Benefits of endoscopic submucosal dissection in rectal polyps are unclear
}

\author{
Aninda Chandra $\cdot$ Biju Aravind $\cdot$ Tarun Singhal $\cdot$ \\ Abdulzahra Hussain
}

Published online: 24 June 2010

(C) Springer Science+Business Media, LLC 2010

This large case series highlights recent advancement in endoscopic management of mucosal lesions of the colon and presents the method with useful figures. We would like to draw attention to a number of details. It would have been useful to have more detail relating to perforation regarding the size, site and type of polyp resected. While one would expect a higher perforation rate on the right side of the colon, in the elderly, or with tumours with deeper invasion level, the authors have not commented on these issues.

Overall, 48 lesions were in the rectum or sigmoid, a region that can be more technically difficult to consider for operative intervention. Presence of lymph nodes for a T1 lesion of colonic wall will change consideration of chemotherapy and corresponds to a $10 \%$ difference in survival at 5 years [1]. Endoscopic ultrasound, particularly in this region, can best determine the depth of invasion of polyps, with accuracy of $61-83 \%$ for lymph node $(\mathrm{N})$ and $93 \%$ for $\mathrm{T}$ staging [2]. This can be further supplemented with magnetic resonance imaging (MRI), which in turn has accuracy of $83 \%$ for $\mathrm{N}$ staging and nearly $100 \%$ for $\mathrm{T}$ staging $[2,3]$, although we appreciate that this does not apply for lesions above the peritoneal fold of rectum or the rest of the colon, with some studies quoting only 54\% specificity and 75\% accuracy [4]. Pre-procedural assessment is important to avoid sub-optimal management, and in this series there were 27 cases of carcinoma that could have been affected. As the case series considered in situ

\footnotetext{
A. Chandra ( $\square)$

General and Colorectal Surgery, Queen Elizabeth Hospital,

Woolwich, England

e-mail: aninda_chandra@hotmail.com

B. Aravind · T. Singhal $\cdot$ A. Hussain

General Surgery, Princess Royal University Hospital,

Orpington, UK
}

and T1 lesions, longer follow-up for comparison with those managed under currently established criteria of cancer management should be considered.

Considering all these issues with the available current evidence, we feel that, while promising, endoscopic submucosal dissection (ESD) technique may not be ideal for rectal or other distal lesions (within $25 \mathrm{~cm}$ of the anal verge) that are amenable to transanal excision or transanal endoscopic micro-surgery (TEMS).

Disclosures Authors A. Chandra, B. Aravind, T. Singhal, and A. Hussain have no conflicts of interest or financial ties to disclose.

\section{References}

1. Govindarajan A, Baxter NN (2008) Lymph node evaluation in early-stage colon cancer. Clin Colorectal Cancer 7:240-246

2. Blomqvist L, Machado M, Rubio C, Gabrielsson N, Granqvist S, Goldman S et al (2000) Rectal tumour staging: MR imaging using pelvic phased-array and endorectal coils vs endoscopic ultrasonography. Eur Radiol 10:653-660

3. Maier AG, Kersting-Sommerhoff B, Reeders JW, Judmaier W, Schima W, Annweiler AA et al (2000) Staging of rectal cancer by double-contrast MR imaging using the rectally administered superparamagnetic iron oxide contrast agent ferristene and IV gadodiamide injection: results of a multicenter phase II trial. J Magn Reson Imaging 12:651-660

4. Chamadol N, Ninpiethoon T, Bhudhisawasd V, Pairojkul C (2005) The role of CT scan in preoperative staging of colorectal carcinoma. J Med Assoc Thai 88:1847-1853 